\title{
STEAP3 promotes cancer cell proliferation by facilitating nuclear trafficking of EGFR to enhance RAC1-ERK-STAT3 signaling in hepatocellular carcinoma
}

\author{
Li-Li Wang ${ }^{1,4}$, Jie Luo ${ }^{1,4}$, Zhang-Hai He${ }^{2}$, Ye-Qing Liu ${ }^{2}$, Hai-Gang $\mathrm{Li}^{2}$, Dan Xie $\mathbb{D}^{1,3 凶}$ and Mu-Yan Cai (iD)
}

(c) The Author(s) 2021

STEAP3 (Six-transmembrane epithelial antigen of the prostate 3, TSAP6, dudulin-2) has been reported to be involved in tumor progression in human malignancies. Nevertheless, how it participates in the progression of human cancers, especially HCC, is still unknown. In the present study, we found that STEAP3 was aberrantly overexpressed in the nuclei of HCC cells. In a large cohort of clinical HCC tissues, high expression level of nuclear STEAP3 was positively associated with tumor differentiation and poor prognosis $(p<0.001)$, and it was an independent prognostic factor for HCC patients. In HCC cell lines, nuclear expression of STEAP3 significantly promoted HCC cells proliferation by promoting stemness phenotype and cell cycle progression via RAC1-ERKSTAT3 and RAC1-JNK-STAT6 signaling axes. Through upregulating the expression and nuclear trafficking of EGFR, STEAP3 participated in regulating EGFR-mediated STAT3 transactivity in a manner of positive feedback. In summary, our findings support that nuclear expression of STEAP3 plays a critical oncogenic role in the progression of HCC via modulation on EGFR and intracellular signaling, and it could be a candidate for prognostic marker and therapeutic target in HCC.

Cell Death and Disease (2021)12:1052; https://doi.org/10.1038/s41419-021-04329-9

\section{INTRODUCTION}

Primary liver cancer is the sixth most common cancer and the fourth leading cause of cancer-related death worldwide, with 841,080 new cases and 781,631 death in 2018. Hepatocellular carcinoma (HCC) accounts for up to $85 \%$ of all primary liver cancer cases $[1,2]$. Early diagnosis of HCC is difficult, and the prognoses of HCC patients haven't been significantly improved due to limited effective therapies, with a 5 -year survival rate of about $18 \%$. 5-year recurrence rates can reach $>70 \%$ even in early-stage HCC patients [3, 4]. Apparently, the high incidence and mortality of HCC call for more effective therapeutic strategies.

STEAP3 is a member of the STEAP family and is composed of a sixtransmembrane domain at the $\mathrm{COOH}$-terminal domain and a cytoplasmic N-terminal oxidoreductase domain, which is essential for iron and copper uptake $[5,6]$. STEAP3 mRNA is highly expressed in the liver, bone marrow, placenta, skeletal muscle, and heart $[5,6]$. In light of the fact that its depletion leads to hypochromic microcytic anemia, STEAP3 plays an important role in the hematopoiesis, especially in erythroid precursors, by regulating iron metabolism $[7,8]$. STEAP3 contains a functional p53-binding site in its promoter and can be upregulated following p53 activation to enhance cell death in myeloid leukemia cell line and breast cancer cells $[9,10]$. By interacting with Nix, a pro-apoptotic Bcl-2 family member, and Myt1 kinase, a negative regulator of the G2/M transition, STEAP3 overexpression promotes apoptosis and inhibits G2/M transition in cell cycle progression $[6,11,12]$. Despite being considered as a tumor suppressor, STEAP3 is involved in the progression of a series of human malignancies. STEAP3 is overexpressed in prostate cancer and metastatic high-grade serous carcinoma $[13,14]$. STEAP3 mRNA level is upregulated to maintain tumor proliferation under hypoferric conditions in colorectal carcinoma [15].

Liver is at the center of iron homeostasis regulation [16]. Through regulating inflammatory responses as well as apoptosis, STEAP3 mediates hepatic ischemia-reperfusion injury via TAK1-dependent activation of the JNK/p38 pathways [17]. Due to its expression being remarkably diminished in HCC nodules compared with cirrhotic peritumoral tissues, STEAP3 was reported to be a marker of the transition from cirrhosis to hepatocellular carcinoma [18, 19]. However, how STEAP3 participates in the progression of HCC is still unknown. Herein, for the first time, we found that an aberrant nuclear expression pattern of STEAP3 which promotes HCC cell proliferation by interacting with EGFR and enhancing EGFR-RAC1-ERK-STAT3 and RAC1-JNK-STAT6 signaling, and it could be employed as a novel prognostic marker and/or effective therapeutic target for human HCC.

\section{MATERIAL AND METHODS}

\section{Cell culture and reagents}

Human HCC cell lines, PLC/PRF/5, QGY-7701, HepG2, Hep3B, SNU449, and Huh-7, were purchased from ATCC, authenticated by STR profiling,

\footnotetext{
${ }^{1}$ State Key Laboratory of Oncology in South China; Collaborative Innovation Center for Cancer Medicine; Sun Yat-Sen University Cancer Center, Guangzhou, Guangdong, China. ${ }^{2}$ Department of Pathology, Sun Yat-Sen Memorial Hospital, Sun Yat-Sen University, Guangzhou, Guangdong, China. ${ }^{3}$ Department of Pathology, Sun Yat-Sen University Cancer Center, Guangzhou, Guangdong, China. ${ }^{4}$ These authors contributed equally: Li-Li Wang, Jie Luo. ${ }^{凶}$ email: xiedan@sysucc.org.cn; caimy@sysucc.org.cn Edited by Professor Stephen Tait
} 
and tested for mycoplasma contamination. The cell lines were maintained in DMEM (Gibco, Thermo Fisher Scientific, Grand Island, NY, USA) supplemented with $10 \%$ fetal bovine serum (Gibco, Thermo Fisher Scientific, Grand Island, NY, USA), 100 units $/ \mathrm{mL}$ penicillin, and $100 \mu \mathrm{g} / \mathrm{mL}$ streptomycin in a $5 \% \mathrm{CO}_{2}$ humidified incubator at $37^{\circ} \mathrm{C}$. DMSO was purchased from Sigma-Aldrich (St. Louis, MO, USA). Primary antibodies and chemicals used in this study were listed in Supplementary Table 1 and Table 2.

\section{Patients}

In this study, formalin-fixed, paraffin-embedded pathological specimens from 200 patients who underwent initial surgical resection between 2003 and 2006 were obtained from the archives of the Department of Pathology of the First Affiliated Hospital of Sun Yat-Sen University (Guangzhou, China). Patients with follow-up data were selected only if they had been given an explicit pathological diagnosis, underwent primary and curative resection, and received no preoperative anticancer treatment. The tumor stage was defined according to the TNM classification of malignant tumors (UICC). Written informed consent was obtained from all patients.

Immunohistochemistry (IHC) and selection of cut-point score HCC tissue slides were incubated with primary antibodies overnight at $4{ }^{\circ} \mathrm{C}$. Immunostaining was performed using the EnVision FLEX Systems (Dako, Santa Clara, CA, USA). Negative control was obtained by replacing the primary antibody with normal goat IgG. The histopathology evaluation in each case was conducted independently by two pathologists in a blind manner. Scores were assigned in a semiquantitative method. In brief, each TMA spot was assigned an intensity score from $0-3(10,11-3)$. Then, the proportion of tumor cells of that intensity was divided by the total number of tumor cells and recorded in $5 \%$ increments from 0 to 100 (P0, P1-3). The final $\mathrm{H}$-score (range $0-300$ ) was determined by adding the sum of the scores obtained for each intensity and the proportion of the area stained $(H$ score $=[11 \times \mathrm{P} 1]+[12 \times \mathrm{P} 2]+[13 \times \mathrm{P} 3])$. X-tile plots were used for the assessment of expression and optimization of cut-point based on the outcome by Miller-Siegmund $P$-value correction.

\section{Western blot}

Whole-cell lysates were prepared with a proteinase inhibitor cocktail and phosphatase inhibitor cocktail (Roche, Alameda, CA, USA). Protein concentrations were determined using the BCA protein assay (Thermo Fisher Scientific, Grand Island, NY, USA). Equal amounts of proteins were subjected to $10 \%$ SDSpolyacrylamide gel electrophoresis and transferred to PVDF membranes (Millipore, Danvers, MA, USA). Membranes were blocked with 5\% non-fat dry milk containing $0.1 \%$ Triton $\mathrm{X}-100$ at room temperature and blotted with primary antibodies overnight at $4{ }^{\circ} \mathrm{C}$. Signals were visualized by chemiluminescence (Thermo Fisher Scientific, Grand Island, NY, USA). Goat anti-rabbit lgG HRP-linked antibody (1:5000) and goat anti-mouse IgG HRP-linked antibody (1:5000) were from Proteintech (Rosemont, IL, USA).

\section{Construction of the recombinant lentiviral vector}

Lv105-STEAP3 and Lv105 control vector, and pGFP-ShLenti-STEAP3 and pGFPShLenti control vector were purchased from GeneCopoeia (Rockville, MD, USA). Stocks of virus were generated in 293-T cell line using Lenti-vpak packaging kit (OriGene, Cambridge, MA, USA). Stably infected cells were selected using puromycin (InvivoGen, CA, USA).

\section{Cell Counting Kit-8 (CCK8) assay}

Cells were seeded in 96 -well plates at a density of 1,000 cells per well. CCK8 (MedChemExpress, NJ, USA) was added to each well and incubated for $1 \mathrm{~h}$ at $37^{\circ} \mathrm{C}$. The optical density (OD) was measured at wavelengths of $450 \mathrm{~nm}$ and $650 \mathrm{~nm}$ using a microplate reader at different time periods. The calibrated OD450 value was calculated as OD450-OD650.

\section{Colony formation assay}

Cells were seeded in 6-well plates at a density of 300 cells per well. The colonies were visualized by staining with crystal violet after 2 weeks.

A
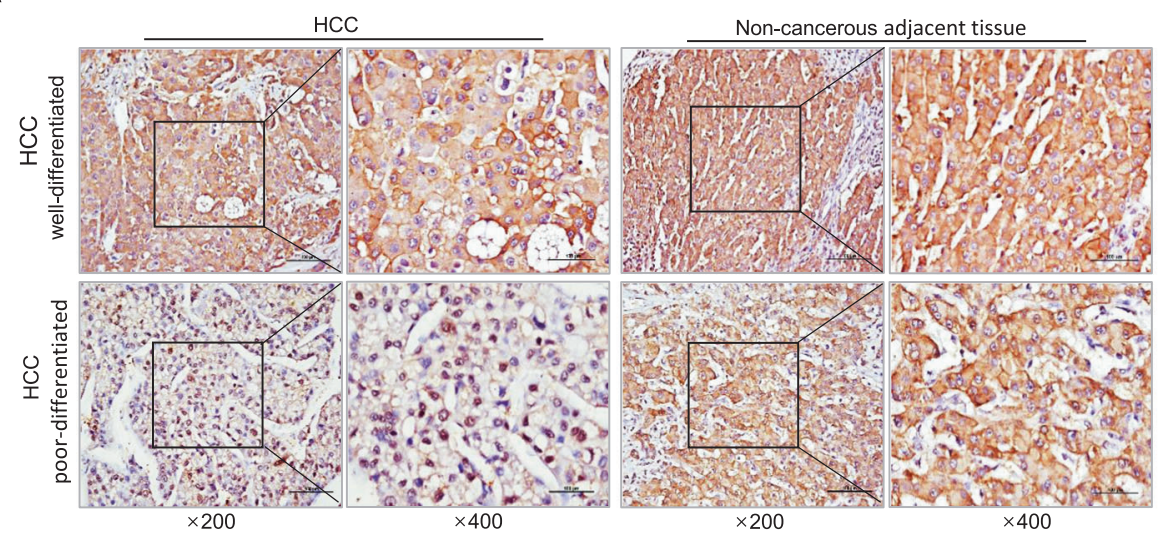

B
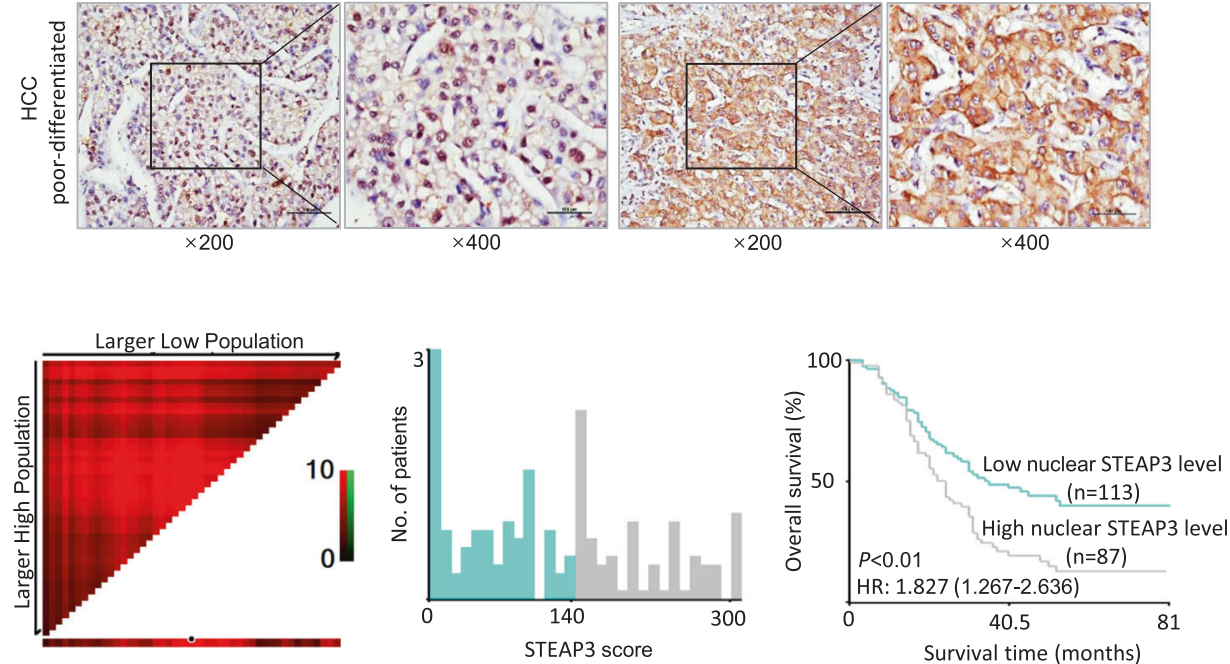

Fig. 1 Nuclear expression of STEAP3 is an independent prognostic factor for poor survival of HCC patients. A Expression levels of STEAP3 were examined by IHC in well- and poor-differentiated HCC tissues (left). Representative images show that STEAP3 was located in the cytoplasm in non-cancerous adjacent tissue (right) and well-differentiated HCC, but distributed in the nuclei in poor-differentiated HCC. Scale bar, $100 \mu$ m. B X-tile plots were employed to determine the cut-point for the nuclear expression of STEAP3 in a large cohort of 200 HCCs. The cut-point was defined as $\mathrm{H}$-score $>140$, and highlighted by the black circle in the horizontal axis (left) and demonstrated on a histogram of the cohort (middle). The $x 2$ log-rank values were defined by Kaplan-Meier method when using the cut-point to divide the cohort into low and high populations, and the $p$-value was determined (right) $(p<0.01)$. 


\section{Sphere formation assay}

Cells were suspended in DMEM/F12 (Gibco, Thermo Fisher Scientific, Grand Island, NY, USA) supplemented with $20 \mathrm{ng} / \mathrm{mL}$ EGF (Gibco, Thermo Fisher Scientific, Grand Island, NY, USA), $20 \mathrm{ng} / \mathrm{mL}$ bFGF (Gibco, Thermo Fisher Scientific, Grand Island, NY, USA), and N-2 supplement (Gibco, Thermo Fisher Scientific, Grand Island, NY, USA), and plated into ultra-low attachment 6-well plates (Corning, Corning, NY, USA) at a density of 300 cells/well for 10 days. Spheroids were counted under an Olympus CKX41 light microscope (Olympus, Tokyo, Japan).

\section{Flow cytometry}

Cells were seeded in 6-well plates, synchronized with serum-free medium for $24 \mathrm{~h}$, and cultured in a medium containing $10 \%$ fetal bovine serum for the indicated period of time. For cell cycle analysis, cells were harvested and fixed in cold $70 \%$ ethanol and analyzed by propidium iodide (PI) staining using the Cell Cycle and Apoptosis Analysis Kit (Beyotime Biotechnology, Shanghai, China).

\section{Transwell assay}

Cells were starved with serum-free medium for $24 \mathrm{~h}$ and seeded at a density of $10^{5}$ in the upper chamber of Transwell chambers with $8 \mu \mathrm{m}$ pore polycarbonate membranes (Corning, NY, USA) in serum-free medium Medium containing 20\% FBS was added to the lower chambers. After incubating for $12 \mathrm{~h}$, cells were stained with crystal violet. Cells crossed through the pores to the lower surface of the filter were counted in 20 high-power fields $(200 x)$ under a microscope.

\section{Tumor growth in xenografts}

$3 \times 10^{6}$ of Hep3B-STEAP3-Sh2 and Hep3B-ShControl cells were injected into the flanks of two groups of 4-week-old male BALB/c nude mice, respectively. Three weeks after subcutaneous inoculation, mice were euthanized, and tumor xenografts were instantly removed and weighed. The sample size was established based on previous work with the animal model. No animal was excluded from the analysis. No randomization was used to allocate samples/animals to experimental groups. The investigator was not blinded to the group allocation of samples/animals.

Table 1. Correlation of nuclear expression of STEAP3 with patients' clinicopathological features in 200 primary hepatocellular carcinomas.

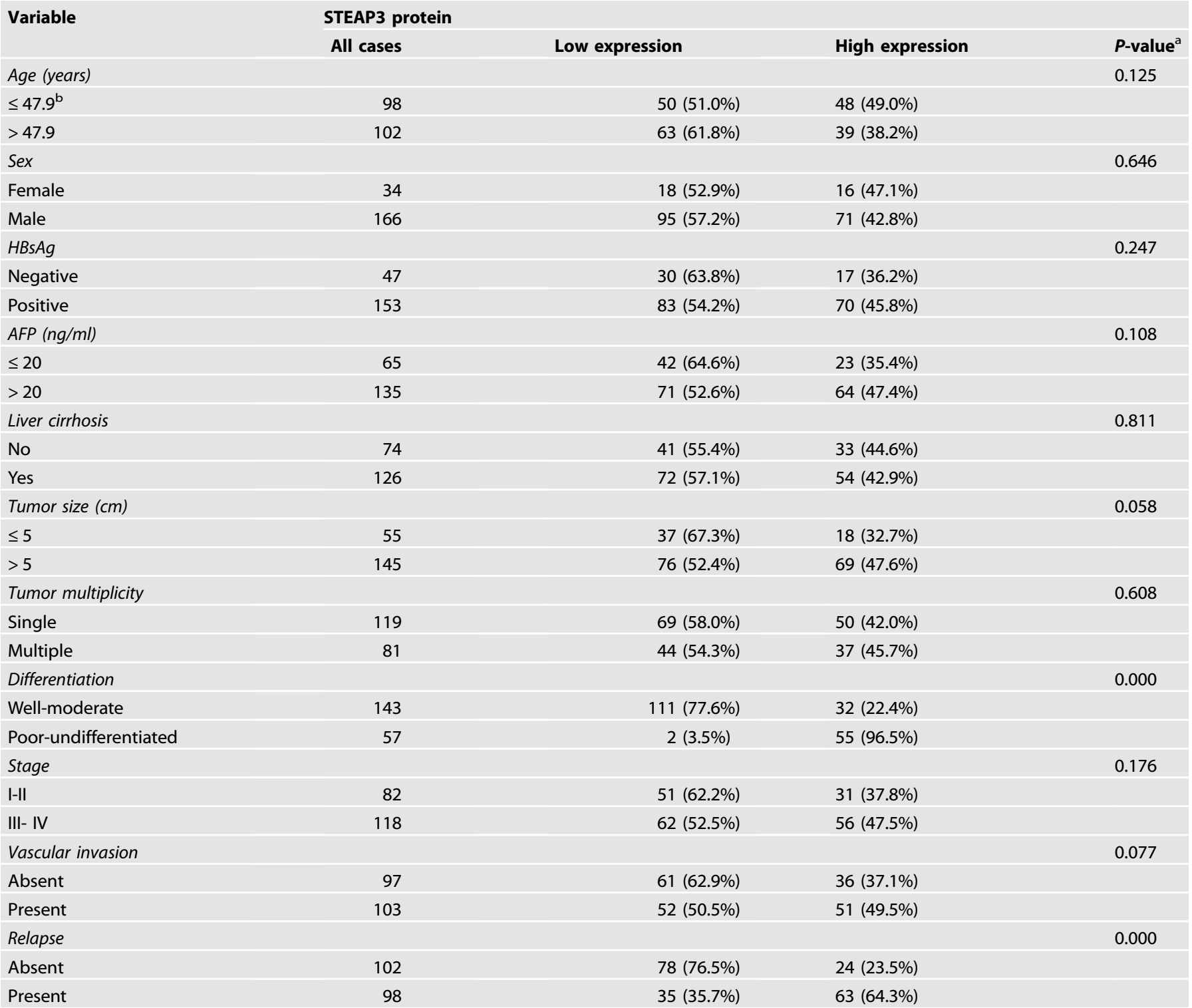

${ }^{\mathrm{a} C h i-s q u a r e}$ test; ${ }^{\mathrm{b}}$ Mean age.

HBsAg hepatitis B surface antigen; AFP alpha-fetoprotein. 


\section{Laser scan confocal microscope}

Cells were seeded on coverslips and allowed to adhere for the indicated period of time. Cells were fixed and permeabilized with cold menthol for 15 min at $-20^{\circ} \mathrm{C}$, then blocked with 5\% BSA in PBS containing 3\% Tween20 for $1 \mathrm{~h}$ at room temperature. Cells were incubated with primary antibodies overnight at $4{ }^{\circ} \mathrm{C}$. After washing, cells were then incubated with a secondary antibody for $1 \mathrm{~h}$ at room temperature. Images were captured using LSM 880 with Airyscan (Zeiss, German) and analyzed using ZEN 2.6 software (Zeiss, German). Anti-rabbit IgG H\&L (Alexa Fluor ${ }^{\circledast}$ 647) $(1: 1000)$ and anti-mouse IgG H\&L (Alexa Fluor $\left.{ }^{\circledR} 594\right)$ (1:1000) were from Abcam (Cambridge, MA, USA).

\section{Co-immunoprecipitation (Co-IP)}

Cell lysates preparation and immunoprecipitation were conducted using Crosslink Magnetic IP/Co-IP Kit (Thermo Fisher Scientific, Grand Island, NY, USA) according to the manufacturer's instructions. The cell lysate was incubated with primary antibodies on a rotator overnight at $4{ }^{\circ} \mathrm{C}$, then subjected to western blot for analysis.

\section{Real-time RT-PCR}

Total RNA from each sample was quantified by the NanoDrop ND-2000 (Thermo Fisher Scientific, Grand Island, NY, USA) and converted to CDNA using PrimeScript ${ }^{T M}$ RT Master Mix (Takara, Kyoto, Japan). Real-time PCR was performed using GoTaq ${ }^{\circledast}$ qPCR Master Mix (Promega, Madison, WI, USA) on a CFX96 Touch Real-Time PCR Detection System (Bio-Rad, California, USA). Primers used in this study were listed in Supplementary Table 3.

\section{Statistical analysis}

For survival analysis, the optimal cut-point for STEAP3 expression was obtained using X-tile software version 3.6.1 (Yale University School of Medicine, New Haven, CT). The correlation between STEAP3 expression and clinicopathological features of HCC patients was analyzed using the $X 2$ test or Fisher's exact test. For univariate survival analysis, survival curves were obtained using the Kaplan-Meier method. A two-sided Student's $t$-test was performed to analyze the statistical significance between two pre-selected groups. $P$-values $<0.05$ were considered statistically significant.

\section{RESULTS}

Nuclear expression of STEAP3 is an independent prognostic factor for the poor outcome of HCC patients

To explore the role of STEAP3 in the progression of HCC, we first examined its expression dynamics by immunohistochemistry in a large cohort of clinical HCC and paired non-cancerous adjacent liver tissues. As reported [18], we found that non-cancerous adjacent liver tissues and well-developed HCC tissues exhibited strong cytoplasm expression of STEAP3, while poor-differentiated HCC tissues showed low STEAP3 expression in the cytoplasm. However, aberrant high levels of STEAP3 were observed in the nuclei of 55 poor-differentiated HCC, which were absent in noncancerous adjacent liver tissues and most of well-differentiated HCC tissues (Fig. 1A). Based on X-tile plots, the cut-point for high nuclear expression of STEAP3 was defined when the $H$-score was above 140 (Fig. 1B). Correlation analysis demonstrated that high nuclear expression of STEAP3 was positively associated with tumor differentiation and relapse $(p<0.001$, Table 1$)$. The mean diseasefree survival time for HCC patients with high nuclear expression of STEAP3 was 29.5 months compared with a survival time of 46.4 months for patients with low nuclear expression of STEAP3 $(p<0.01$, log-rank test, Table 2). Furthermore, nuclear STEAP3 expression is an independent prognostic factor for poor survival of HCC patients ( $p<0.05$, multivariate Cox regression).

\section{Enhanced nuclear expression of STEAP3 promotes cancer cell proliferation in HCC}

To validate the functional significance of aberrant nuclear expression of STEAP3 as observed in HCC tissues, we first examined its expression level in HCC cell lines and immortalized hepatocyte MIHA (Fig. 2A), and accordingly established HCC cell lines in which STEAP3 was stably upregulated (PLC/PRF/5-STEAP3)
Table 2. Univariate analysis of nuclear expression of STEAP3 and clinicopathologic variables in 200 patients with primary hepatocellular carcinomas (log-rank test).

\begin{tabular}{|c|c|c|c|}
\hline Variables & All cases & RR $(95 \% \mathrm{Cl})$ & $P$-value \\
\hline Age (years) & & & 0.655 \\
\hline$\leq 47.9^{\mathrm{a}}$ & 98 & 1.0 & \\
\hline$>47.9$ & 102 & $1.085(0.759-1.550)$ & \\
\hline Sex & & & 0.049 \\
\hline Female & 34 & 1.0 & \\
\hline Male & 166 & $1.687(0.996-2.856)$ & \\
\hline$H B s A g$ & & & 0.684 \\
\hline Negative & 47 & 1.0 & \\
\hline Positive & 153 & $1.093(0.712-1.678)$ & \\
\hline AFP $(\mathrm{ng} / \mathrm{ml})$ & & & 0.000 \\
\hline$\leq 20$ & 65 & 1.0 & \\
\hline$>20$ & 135 & $2.196(1.441-3.347)$ & \\
\hline Liver cirrhosis & & & 0.584 \\
\hline No & 74 & $0.902(0.625-1.303)$ & \\
\hline Yes & 126 & 1.0 & \\
\hline Tumor size $(\mathrm{cm})$ & & & 0.000 \\
\hline$\leq 5$ & 55 & 1.0 & \\
\hline$>5$ & 145 & $6.107(3.520-10.597)$ & \\
\hline Tumor multiplicity & & & 0.000 \\
\hline Single & 119 & 1.0 & \\
\hline Multiple & 81 & $3.396(2.349-4.911)$ & \\
\hline Differentiation & & & 0.037 \\
\hline Well-moderate & 143 & 1.0 & \\
\hline Poor-undifferentiated & 57 & $1.483(1.023-2.149)$ & \\
\hline Stage & & & 0.000 \\
\hline I-II & 82 & 1.0 & \\
\hline III-IV & 118 & $5.667(3.622-8.866)$ & \\
\hline Vascular invasion & & & 0.000 \\
\hline Absent & 97 & 1.0 & \\
\hline Present & 103 & $5.164(3.409-7.823)$ & \\
\hline Relapse & & & 0.001 \\
\hline Absent & 102 & 1.0 & \\
\hline Present & 98 & $1.878(1.299-2.717)$ & \\
\hline STEAP3 expression & & & 0.001 \\
\hline Low & 113 & 1.0 & \\
\hline High & 87 & $1.866(1.302-2.676)$ & \\
\hline
\end{tabular}

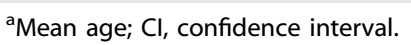

HBsAg hepatitis B surface antigen; AFP alpha-fetoprotein.

or knockdown (Hep3B-ShSTEAP3 and SNU449-ShSTEAP3) (Fig. 2B). Then, by examining its subcellular localization, an enhanced nuclear distribution of STEAP3 was confirmed in PLC/PRF/5STEAP3 $(p<0.01$, Fig. 2C). Subsequently, functional assays were adopted to explore the effects of altered STEAP3 expression on cell proliferation. Compared to paired control cells, PLC/PRF/5STEAP3 exhibited increased cell viability $(p<0.01$, Fig. 2D) and colony formation ( $p<0.05$, Fig. 2E). Meanwhile, Hep3B-ShSTEAP3 and SNU449-ShSTEAP3 showed decreased cell viability $(p<0.01$, Fig. 2D) and colony formation ( $p<0.05$, Fig. 2E). In addition, the expression level of proliferation index PCNA was significantly increased in PLC/PRF/5-STEAP3 but decreased in Hep3B-ShSTEAP3 and SNU449-ShSTEAP3 (Fig. 2F). Furthermore, to validate the in vivo effect of STEAP3 on tumor growth, a xenograft mouse 
A

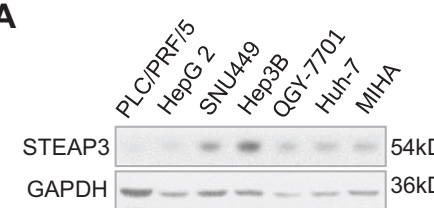

C

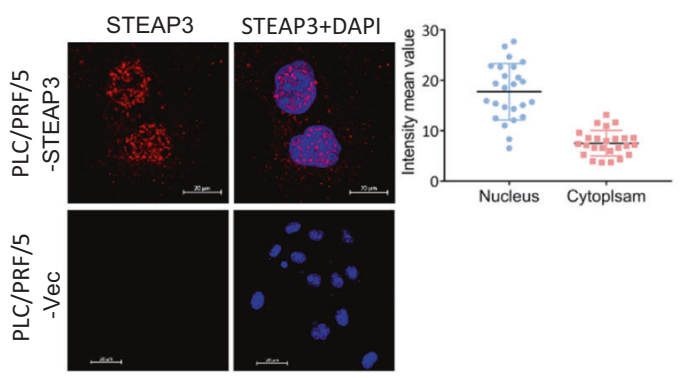

E
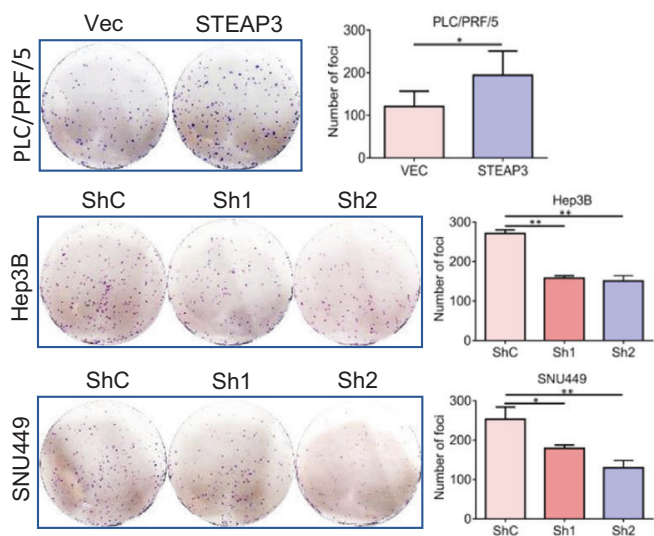

H
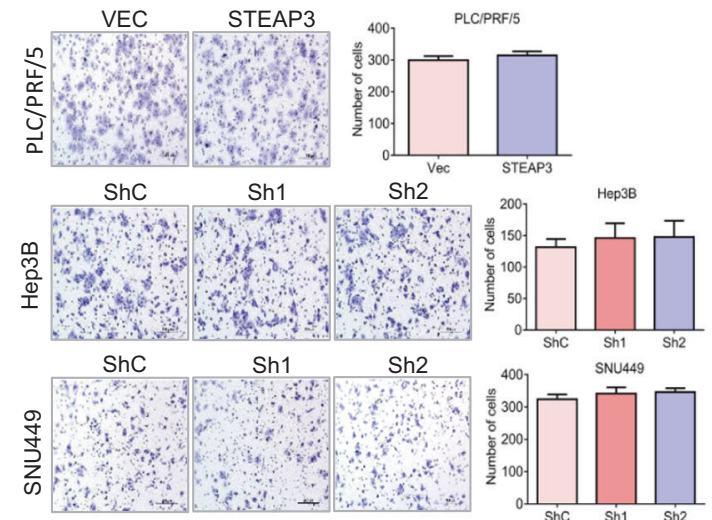

B

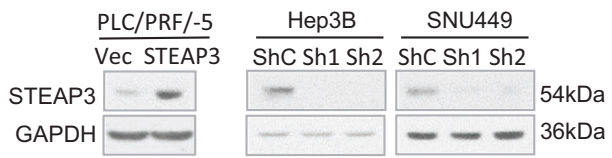

D

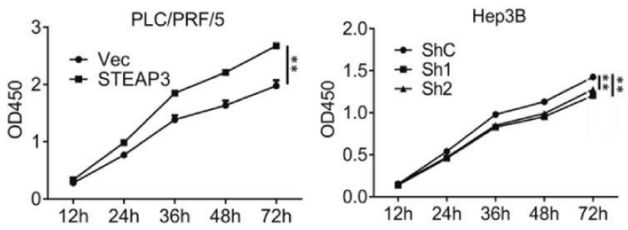

SNU449

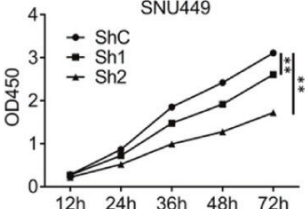

$\mathbf{F}$

$\frac{\mathrm{PLC} / \mathrm{PRF} / \mathrm{-5}}{\mathrm{Vec} \text { STEAP3 }} \frac{\text { Hep3B }}{\text { ShC Sh1 Sh2 ShC Sh1 Sh2 }}$

PCNA $--\infty-\ldots$ - $-\ldots \mathrm{kDa}$

GAPDH $=36 \mathrm{kDa}$

G

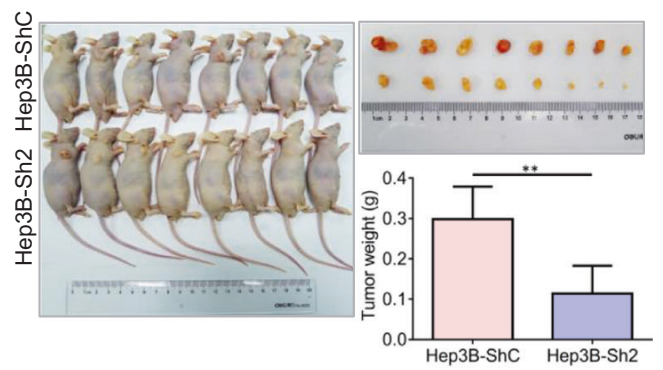


A

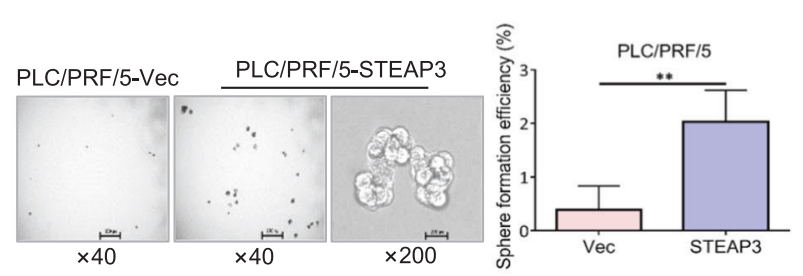

B
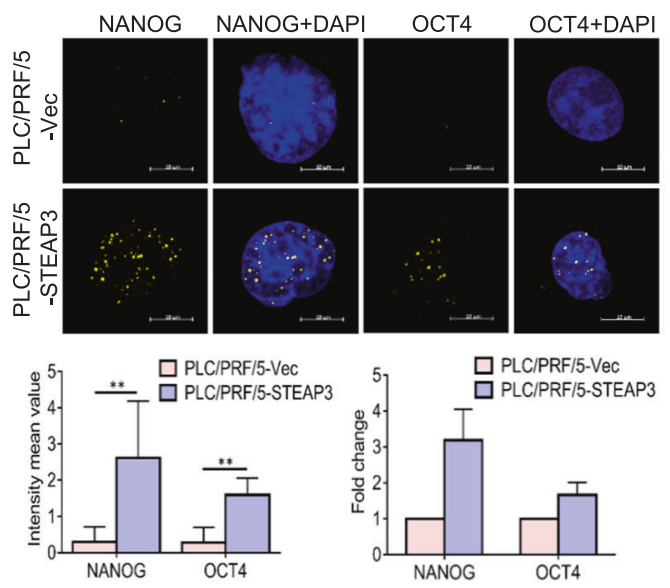

$\mathbf{F}$
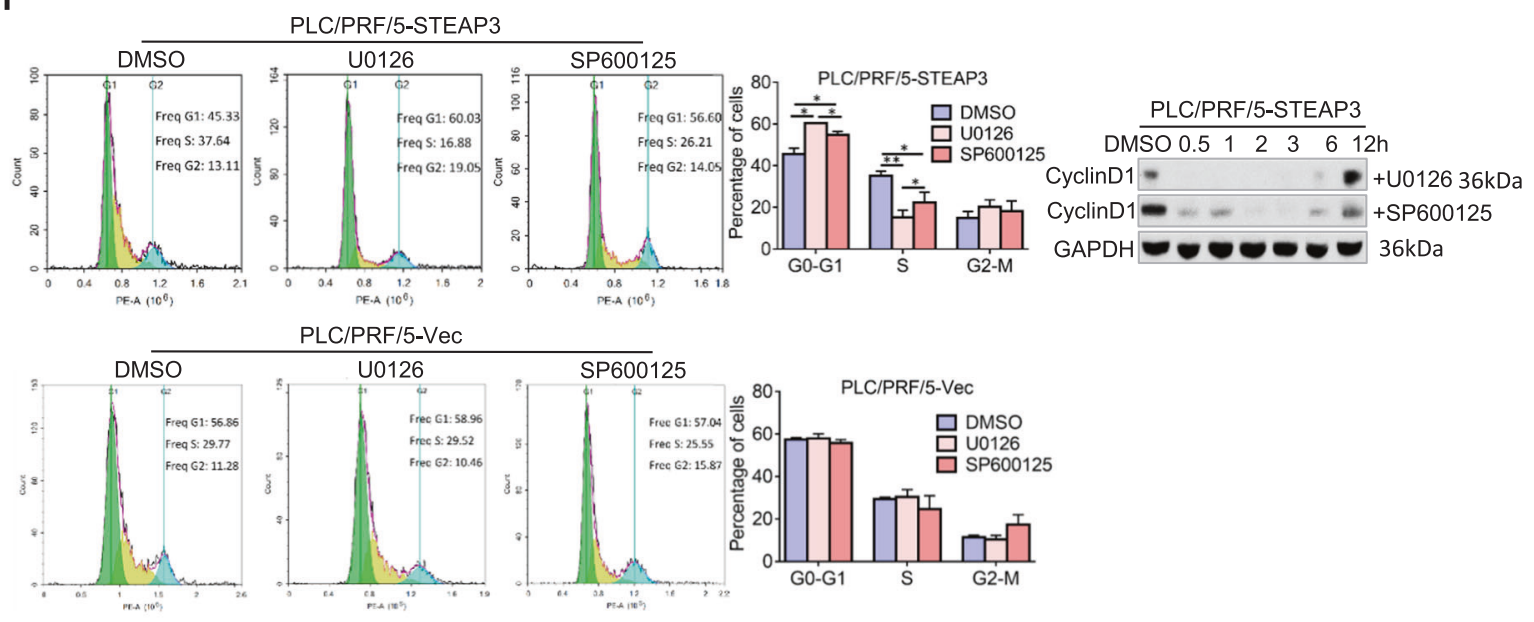

G
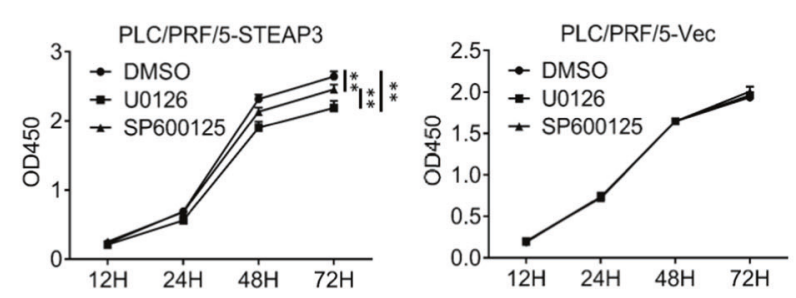

C
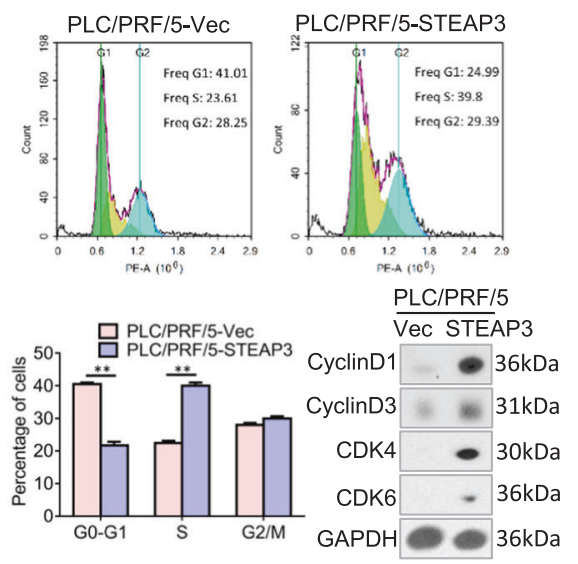

D

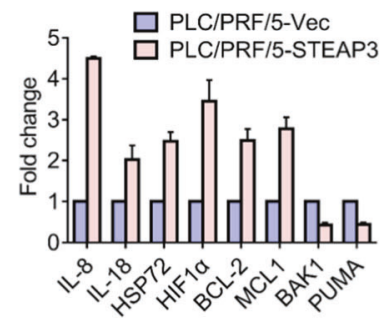

E

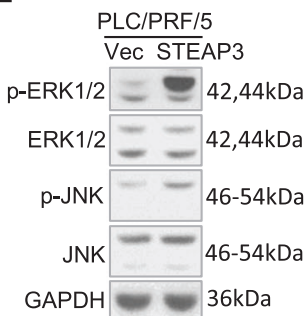

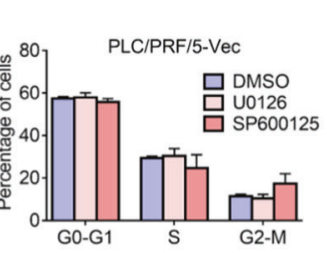

H

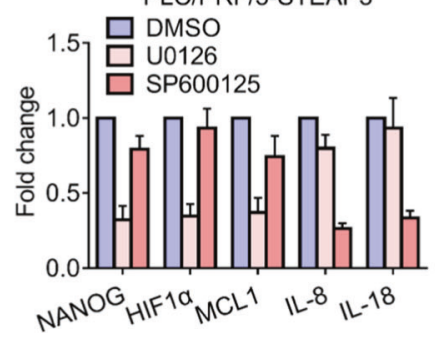

model was carried out (Fig. 2G). As expected, the group of mice injected with Hep3B-ShSTEAP3 developed remarkably smaller and lighter tumor masses than that of the control group $(p<0.01$, Fig. $2 \mathrm{G})$. Nevertheless, aberrant expression of STEAP3 didn't significantly affect cell motility and invasion as examined by our transwell assays ( $p>0.05$, Fig. $2 \mathrm{H}$, Supplementary Fig. 1).
STEAP3 modulates ERK and JNK signaling to promote stemness and cell cycle progression in HCC

To reveal how aberrant nuclear expression of STEAP3 promotes HCC cells proliferation, we first examined its modulation on stemness phenotype. As compared with control cells, PLC/PRF/5STEAP3 exhibited much higher sphere-propagating capacity 
Fig. 3 STEAP3 modulates ERK and JNK signaling to promote stemness and cell cycle progression in HCC. A Representative images of morphology of spheroids in PLC/PRF/5-STEAP3 and control cells were showed. Sphere formation efficiency (SFE) was calculated and presented as means \pm SD of three independent experiments. Scale bar, 200px. ${ }^{* *} p<0.01$. B Expression levels of NANOG and OCT4 (yellow) were examined by IF in PLC/PRF/5-STEAP3 and control cells. Nuclei were visualized by DAPI (blue). Fluorescence intensity mean values were measured in 30 cells that showed strong fluorescence in each group and presented as means \pm SD (left, lower panel). Scale bar, $10 \mu \mathrm{m}$. ${ }^{* *} p<0.01$. mRNA levels of NANOG and OCT4 were examined by real-time RT-PCR and presented as means \pm SD of three independent experiments (right, lower panel). C Cell cycle was analyzed by flow cytometry after cells were synchronized by starvation and supplemented with serum for $8 \mathrm{~h}$ in PLC/PRF/5-STEAP3 and control cells (upper panel). Data are presented as means \pm SD of three independent experiments. ${ }^{* *} p<0.01$ (left, lower panel). Expression levels of CyclinD1, CyclinD3, CDK4, and CDK6 were examined by western blot (right, lower panel). D mRNA levels of inflammatory factors (IL-8, IL-18, and HSP72), HIF1 $\alpha$, and BCL-2 family members (BCL-2, MCL1, BAK1, and PUMA) were examined by real-time RT-PCR and presented as means \pm SD of three independent experiments. E Phosphorylation levels of ERK1/2 and JNK were examined by western blot in PLC/PRF/5-STEAP3 and control cells. F PLC/PRF/5-STEAP3 and PLC/PRF/5-Vec cells were synchronized by starvation, administrated with U0126 (10 $\mu$ M, $2 \mathrm{~h})$, and SP600125 (50 $\mu \mathrm{M}$, $45 \mathrm{~min}$ ), respectively, and supplemented with serum for $8 \mathrm{~h}$. Cell cycle was analyzed by flow cytometry. Cells administrated with DMSO were used as a control. Data are presented as means \pm SD of three independent experiments. ${ }^{*} p<0.05,{ }^{* *} p<0.01$. Expression levels of CyclinD1 were examined by western blot in PLC/PRF/5-STEAP3. G Cell viability was examined by CCK8 assays in PLC/PRF/5-STEAP3, and PLC/PRF/5-Vec treated with U0126 and SP600125, respectively. Cells administrated with DMSO were used as a control. Data are presented as means \pm SD of three independent experiments. ${ }^{* *} p<0.01$. H mRNA levels of NANOG, HIF1 $\alpha$, MCL1, IL-8, and IL-18, after administration with U0126 and SP600125 in $\mathrm{PLC} / \mathrm{PRF} / 5-\mathrm{STEAP3}$, were examined by real-time RT-PCR and presented as means \pm SD of three independent experiments.

$(p<0.01$, Fig. 3A). Consistently, both protein and mRNA levels of pluripotency transcription factors, NANOG and OCT4, were elevated in PLC/PRF/5-STEAP3, reflecting that nuclear STEAP3 participated in promoting stemness phenotype (Fig. 3B). Subsequently, by monitoring cell cycle progression, we found that PLC/ PRF/5-STEAP3 passed through G1 checkpoint much faster than control cells, and correspondingly, G1 Cyclins (Cyclin D1 and Cyclin D3) and CDKs (CDK4 and CDK6) levels were significantly upregulated compared with that in control cells ( $p<0.01$, Fig. 3C). In addition, we found that inflammatory factors (IL-8, IL-18, and HSP72), HIF1a, and anti-apoptotic proteins (BCL-2 and MCL1) were substantially transcriptionally upregulated by STEAP3, while proapoptotic proteins (BAK1 and PUMA) were downregulated (Fig. 3D).

To further clarify the intracellular signaling that mediated the pro-proliferation effect of STEAP3, we focused on MAPK pathways, which play essential roles in regulating cell survival and proliferation. We found that ERK and JNK activities were substantially upregulated, as evidenced by increased phosphorylation of ERK $1 / 2$ and JNK (Fig. 3E). Then, by adopting specific ERK and JNK inhibitors, U0126 and SP600125, we explored their individual role in cell proliferation. Inhibition on ERK and JNK, especially on ERK, significantly repressed G1/S transition $(p<0.05$, Fig. 3F, upper panel) and cell viability ( $p<0.01$, Fig. 3G, left), while, didn't affect cell cycle progression ( $p>0.05$, Fig. 3F, lower panel) and cell viability in PLC/PRF/5-Vec $(p>0.05$, Fig. 3G, right). Furthermore, ERK inhibition abrogated STEAP3-induced upregulation of NANOG, HIF1a, and MCL1 transcription, while JNK inhibition only decreased IL-8 and IL-18 transcription (Fig. 3H). These results suggested that ERK signaling played a more vital part in STEAP3-enhanced cell proliferation, even though both ERK and JNK signaling contributed.

STEAP3 regulates RAC1 to activate ERK-STAT3/JNKSTAT6 signaling axes to promote cell proliferation in HCC STAT (Signal transducers and activators of transcription) is one of the most important downstream transcription factors utilized by various pro-proliferation signals. Therefore, to further reveal how STEAP3promoted cell proliferation, we examined its regulation on STAT family members. Our results showed that STEAP3 significantly upregulated the expression levels and nuclear translocation of p-STAT3 Ser727 and p-STAT6 Tyr641 (Fig. 4A, B). To verify to what extent did they individually participate in STEAP3-induced signaling, we adopted specific STAT3 and STAT6 inhibitors, C188-9, and AS1517499, respectively, to block their activation. As compared to control cells, STAT3 inhibition led to much more massive cell death under starvation-induced stress in PLC/PRF/5-STEAP3 (Fig. 4C, upper panel), while STAT6 inhibition barely affected cell survival (Fig. 4C, lower panel). Furthermore, STAT3 inhibition decreased cell viability to a greater extent than STAT6 inhibition $(p<0.01$, Fig. 4D). These results strongly indicated that STAT3 played a more important part in modulating cell proliferation induced by STEAP3.

Subsequently, by utilizing U0126 and SP600125, we found that ERK inhibition significantly decreased the expression of p-STAT3 Ser727, while JNK inhibition blocked STAT6 activation, suggesting that ERK-STAT3, and JNK-STAT6 signaling axes participated in mediating STEAP3-promoted cell proliferation (Fig. 4E). Consistently, STAT3 inhibition decreased NANOG and MCL1 transcription, while STAT6 inhibition reduced the transcription of IL-8 and IL-18 (Fig. 4F).

The Rho family of small GTPases acts as molecular switches to regulate the activation of signaling pathways, including MAPK pathways. Hence, we examined the expression levels of the members of this family and found that RAC1 was considerably upregulated by STEAP3 (Fig. 4G). Through inhibiting RAC1 by a specific inhibitor, EHop-016, we further established that RAC1 was the upstream activator of ERK-STAT3/JNK-STAT6 signaling, in light of that these signaling was notably abrogated by EHop-016 administration (Fig. 4H).

\section{STEAP3 facilitates nuclear trafficking of EGFR to enhance STAT3 transactivity}

Growth factor receptors, which have long been recognized as oncogenic proteins, are the most common activators of MAPK signaling and are involved in cancer growth/progression. We found that EGFR (epidermal growth factor receptor, ErbB-1/HER-1) was significantly upregulated by STEAP3 on both protein and mRNA levels (Fig. 5A). Similar to STEAP3, we observed enhanced nuclear translocation of EGFR in PLC/PRF/5-STEAP3, compared with control cells $(p<0.01$, Fig. 5B). Then, a clear interaction between STEAP3 and EGFR was validated in both PLC/PRF/5STEAP3 and HEK293 (Fig. 5C, D). In addition, STEAP3 complexed with EGFR in the nuclear membrane (Fig. 5D, right, gray triangle) and nucleoplasm, besides in the cytoplasm (Fig. 5D, right, orange triangle), in PLC/PRF/5-STEAP3, implicating that STEAP3 participated in facilitating nuclear trafficking of EGFR. Furthermore, STEAP3-induced activation of ERK and STAT3, not that of JNK, was substantially abrogated by EGFR inhibition (Fig. 5E). In agreement with reports that nuclear EGFR requires co-factors, such as STAT3 [20], to transactivate target genes, the interaction between EGFR and p-STAT3 Ser727 was found in PLC/PRF/5-STEAP3 (Fig. 5F). These results clearly indicated that STEAP3 not only facilitated the nuclear trafficking of EGFR but also complexed with it in the nucleus, to enhance the transactivity of STAT3.

Since RAC1 was increasingly translocated to the nucleus in cancer cells [21], we subsequently examined the spatio-temporal coordination of EGFR with RAC1. As our results showed, RAC1 inhibition significantly decreased the expression level of EGFR in PLC/PRF/5STEAP3 (Fig. 5G). The great magnitude of G1/S transition was completed in the first $8 \mathrm{~h}$ of a cell cycle in PLC/PRF/5-STEAP3 (Fig. 3C). During this period of time, RAC1 and EGFR first co-localized in 
A

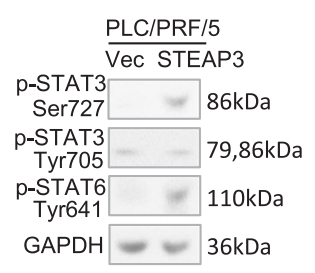

C

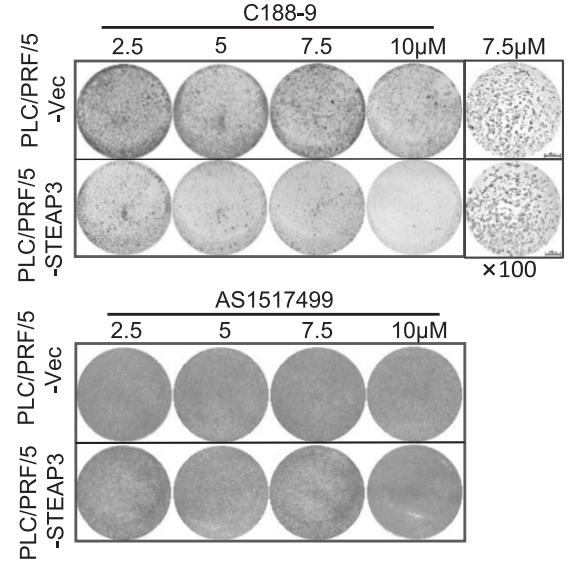

F

G
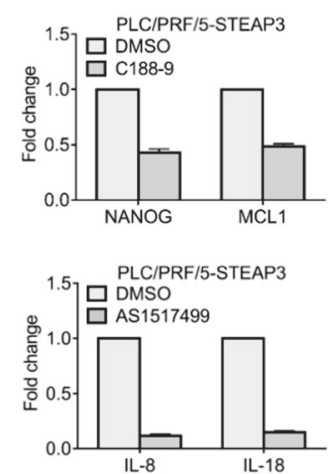

B

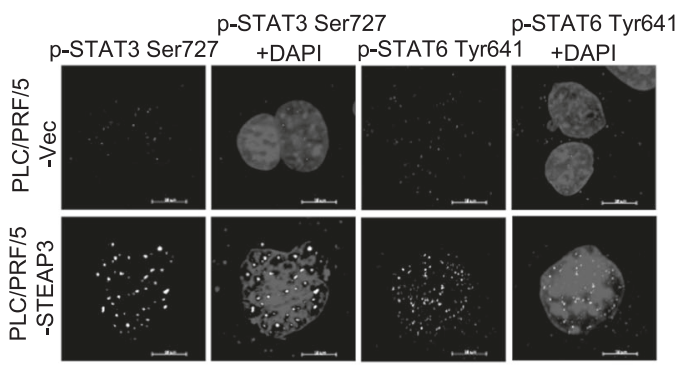

D

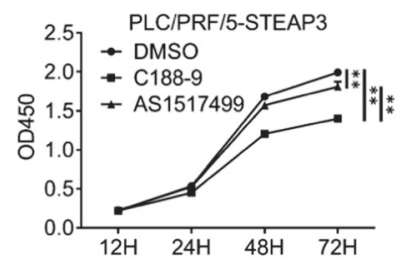

E

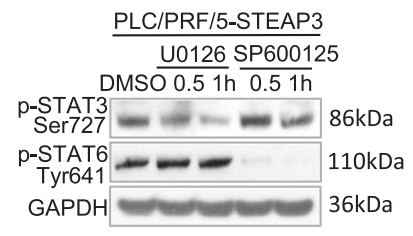

H

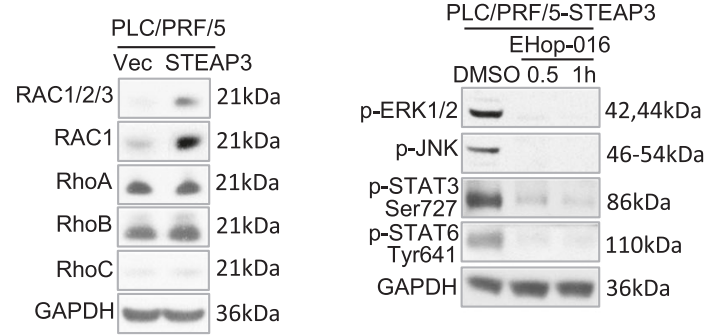

Fig. 4 STEAP3 regulates RAC1 to activate ERK-STAT3/JNK-STAT6 signaling axes to promote cell proliferation in HCC. A Phosphorylation levels of STAT3 and STAT6 were examined by western blot. B Nuclear translocation of p-STAT3 Ser727 and p-STAT6 Tyr641 was verified by IF in PLC/ PRF/5-STEAP3 and control cells. Nuclei were visualized by DAPI (blue). Scale bar, $10 \mu \mathrm{m}$. C PLC/PRF/5-STEAP3 and control cells were starved for $24 \mathrm{~h}$, then supplemented with serum and administrated with different doses $(2.5,5,7.5,10 \mu \mathrm{M})$ of STAT3 and STAT6 inhibitor, C188-9 and AS1517499, respectively, for $2 \mathrm{~h}$. Scale bar, $200 \mu \mathrm{m}$. Cells were fixed, and visualized by crystal violet. D Cell viability was examined by CCK8 assays in PLC/PRF/5-STEAP3 treated with C188-9 $(0.5 \mu \mathrm{M})$ and AS1517499 $(1 \mu \mathrm{M})$, respectively. Cells administrated with DMSO were used as a control. Data are presented as means \pm SD of three independent experiments. ${ }^{* *} p<0.01$. E Phosphorylation levels of STAT3 Ser727 and STAT6 Tyr641 were examined by western blot after U0126 and SP600125 administration for 0.5 and $1 \mathrm{~h}$, respectively, in PLC/PRF/5-STEAP3. F mRNA levels of NANOG, MCL1, IL-8 and IL-18, were examined by real-time RT-PCR in PLC/PRF/5-STEAP3 after administration with C188-9 and AS1517499, respectively, and presented as means \pm S.D. of three independent experiments. G Expression levels of Rho GTPase family members (RAC1/2/3, RAC1, RhoA, RhoB, and RhoC) were examined by western blot in PLC/PRF/5-STEAP3 and control cells. H Phosphorylation levels of ERK1/2, JNK, STAT3 Ser727, and STAT6 Tyr641 were examined by western blot in PLC/PRF/5-STEAP3 after RAC1 inhibition by EHop-016 (5 $\mu$ M) for 0.5 and $1 \mathrm{~h}$.

the cytoplasm, then nuclear translocation of RAC1 preceded and peaked before nuclear trafficking of EGFR, suggesting that RAC1 might exert other functions besides molecular switch in PLC/PRF/5STEAP3 (Fig. 5H). Then, a clear co-localization between RAC1 and Lamin $A / C$, which is a nuclear structural component mainly found in the nuclear lamina, was observed (Supplementary Fig. 2). These results indicated that RAC1 might participate in regulating nuclear structure to facilitate EGFR nuclear trafficking.
Furthermore, we evaluated the potential correlations between the nuclear expression of STEAP3 and EGFR by IHC in our cohort of 200 HCC tissues (Fig. 5I). Our results showed that the nuclear expression of STEAP3 was positively correlated with that of EGFR $(p<0.001$, Chi-square test, Table 3).

Together, these results suggested that STEAP3 initiated a positive feedback loop that acted through EGFR (EGFR, RAC1, ERK) to modulate the transactivity of STAT3. 
A

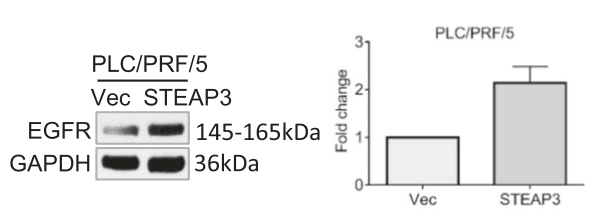

B

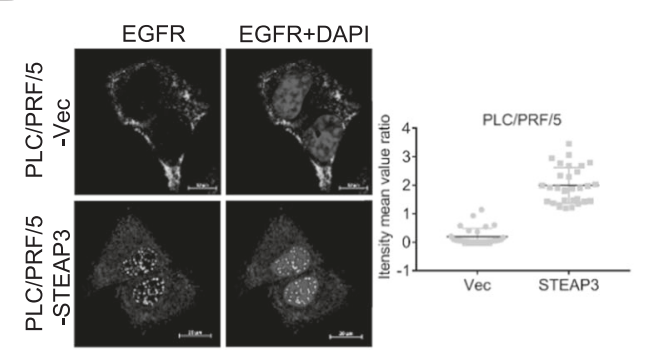

E

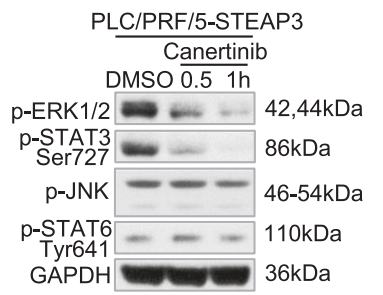

H

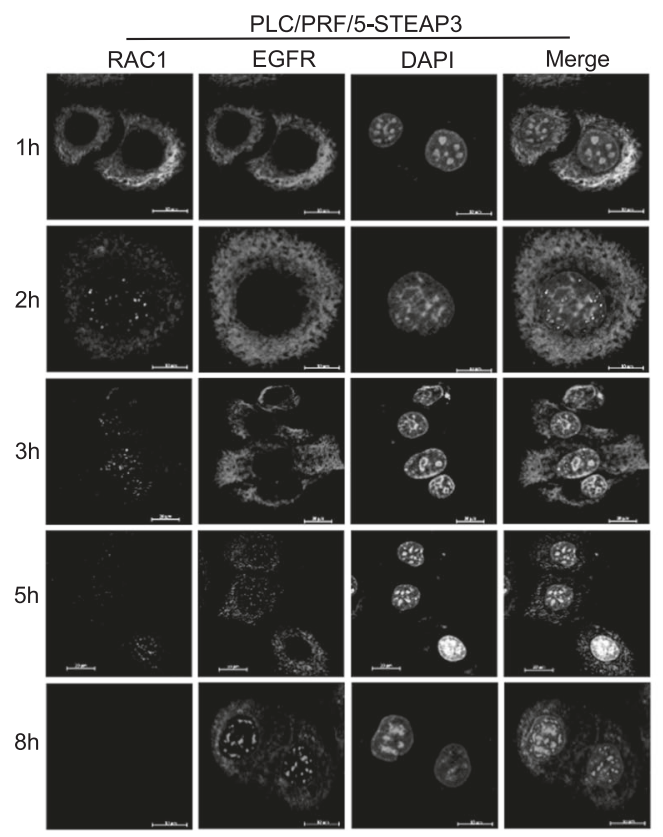

C

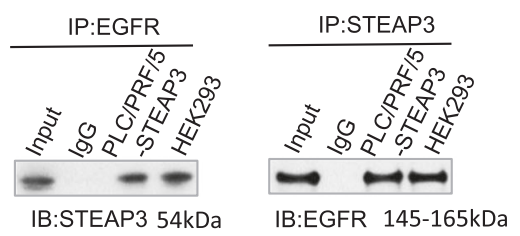

$\mathbf{F}$

D

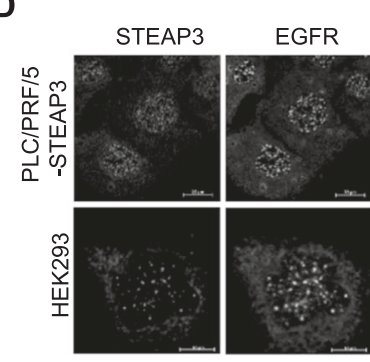

PLC/PRF/5-STEAP3

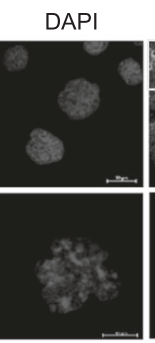

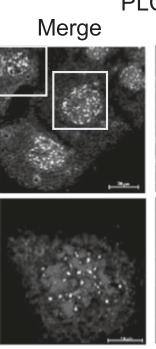

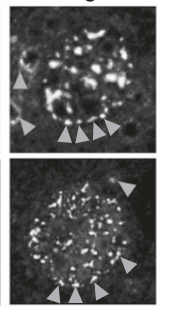

G
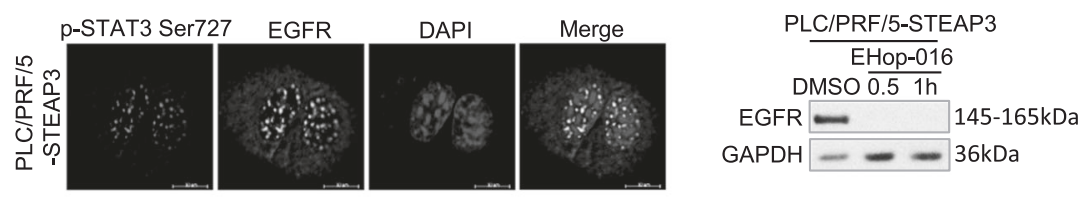

I

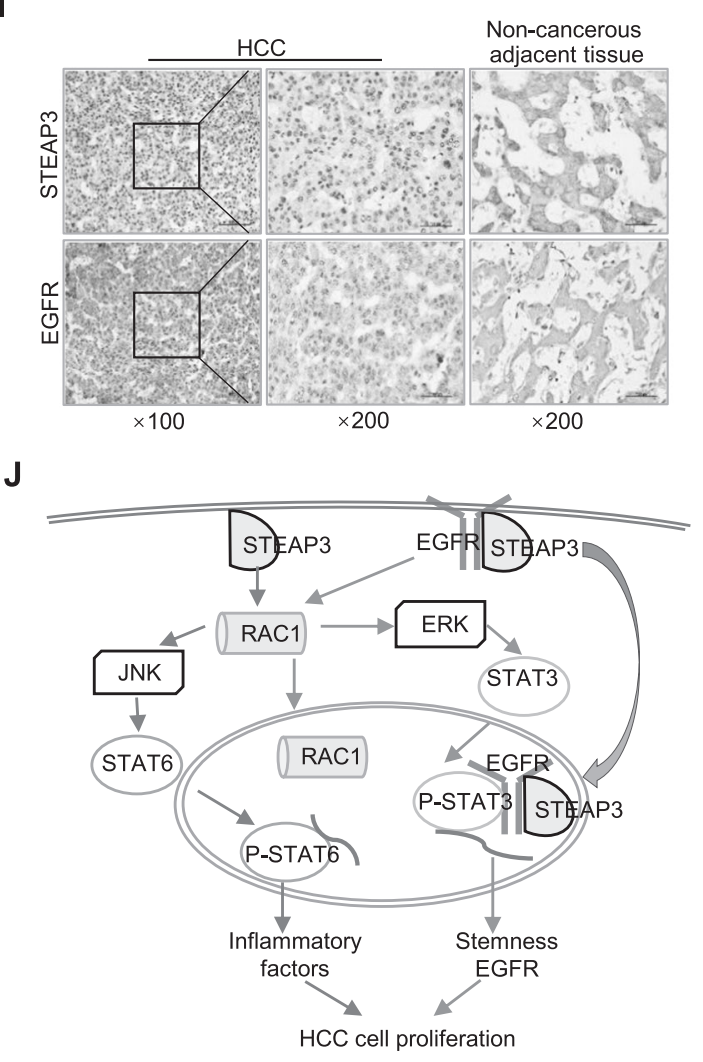

its oncogenic role are largely unknown. In the present study, unprecedently, we observed that STEAP3 was aberrantly overexpressed in the nuclei of HCC cells, which positively associated with tumor differentiation and poor prognosis. Using a series of 
Fig. 5 STEAP3 facilitates nuclear trafficking of EGFR to enhance STAT3 transactivity. A Protein and mRNA levels of EGFR were examined by western blot (left) and real-time RT-PCR (right), respectively, in PLC/PRF/5-STEAP3 and control cells. Data are presented as means \pm SD of three independent experiments. B PLC/PRF/5-STEAP3 and control cells were synchronized by starvation and supplemented with serum for $8 \mathrm{~h}$. Subcellular distribution of EGFR was examined by IF, and the fluorescence intensity mean values of that were measured in randomly chose 30 cells (left). Scale bar, $10 \mu \mathrm{m}$ and $20 \mu \mathrm{m}$. Intensity means value ratios were determined by comparing the intensity mean values in the nuclei with that in the cytoplasm (right). $p<0.01$. C Interaction between STEAP3 and EGFR was analyzed in PLC/PRF/5-STEAP3 and HEK293 by Co-IP assay. D Colocalization of STEAP3 (red) with EGFR (green) was verified by confocal microscope in PLC/PRF/5-STEAP3 (left, upper panel) and HEK293 (left, lower panel). Magnified images with merged STEAP3 and EGFR fluorescence signals in PLC/PRF/5-STEAP3 were shown (right). Nuclei were visualized by DAPI (blue). Scale bar, $10 \mu \mathrm{m}$ and $20 \mu \mathrm{m}$. E Phosphorylation levels of ERK1/2, JNK, STAT3 Ser727, and STAT6 Tyr641 were examined by western blot in PLC/PRF/5-STEAP3 after EGFR inhibition using Canertinib $(5 \mu \mathrm{M})$ for 0.5 and $1 \mathrm{~h}$. Cells administrated with DMSO were used as a control. F Colocalization of p-STAT3 Ser727 (red) with EGFR (green) was examined by confocal microscope in PLC/PRF/5-STEAP3. Nuclei were visualized by DAPI (blue). Scale bar, $10 \mu \mathrm{m}$. G Expression level of EGFR was examined by western blot in PLC/PRF/5-STEAP3 after EHop-016 (5 $\mu$ M) administration for 0.5 and $1 \mathrm{~h}$, respectively. Cells administrated with DMSO were used as a control. H PLC/PRF/5-STEAP3 cells were synchronized by starvation and supplemented with serum for indicated periods of time $(1,2,3,5$, and $8 \mathrm{~h}$ ), respectively. Subcellular distributions of RAC1 (green) and EGFR (red) were examined by confocal microscope. Nuclei were visualized by DAPI (dark gray). Scale bar, $10 \mu \mathrm{m}$ and $20 \mu \mathrm{m}$. I Expression levels of STEAP3 and EGFR were examined by IHC on HCC and paired non-cancerous adjacent tissues. Representative images showed that STEAP3 and EGFR were overexpressed in the nuclei in HCC cells compared with that in non-cancerous adjacent tissues. Scale bar, $100 \mu \mathrm{m}$. J Graphic abstract depicting a proposed model for a major mechanism of STEAP3 in promoting HCC cell proliferation.

Table 3. Correlation between nuclear expression of STEAP3 and EGFR in hepatocellular carcinomas.

\begin{tabular}{|c|c|c|c|c|}
\hline & \multicolumn{4}{|c|}{ Nuclear EGFR expression } \\
\hline & Low & High & Total & $P$-value ${ }^{*}$ \\
\hline \multicolumn{5}{|c|}{ Nuclear STEAP3 expression } \\
\hline Low & $\begin{array}{l}100 \\
(88.5 \%)\end{array}$ & $\begin{array}{l}13 \\
(11.5 \%)\end{array}$ & $\begin{array}{l}113 \\
(56.5 \%)\end{array}$ & 0.000 \\
\hline High & $38(43.7 \%)$ & $\begin{array}{l}49 \\
(56.3 \%)\end{array}$ & $87(43.5 \%)$ & \\
\hline Total & $\begin{array}{l}138 \\
(69.0 \%)\end{array}$ & $\begin{array}{l}62 \\
(31.0 \%)\end{array}$ & 200 & \\
\hline
\end{tabular}

${ }^{*}$ Chi-square test.

in vitro and in vivo assays, we provided evidence that nuclear STEAP3 significantly enhances HCC cells proliferation by promoting stemness phenotype and cell cycle progression via upregulating the expression and nuclear trafficking of EGFR and modulating EGFR-RAC1-ERK-STAT3 and RAC1-JNK-STAT6 signaling axes. These results strongly support the oncogenic role of STEAP3 in the progression of $\mathrm{HCC}$, and it could be an independent prognostic marker to predict patients' outcomes.

Previous studies showed that STEAP3 localizes in the plasma membrane, near the nucleus, and in vesicular tubular structures [10]. It is upregulated upon p53 activation and involved in promoting apoptosis and cell cycle delay in the G2/M phase by interacting with Nix and Myt1 [6, 11, 12]. In addition, enhanced STEAP3 expression facilitates and promotes the vesicular secretion of TCTP, a tubulin-binding protein that participates in regulating cytoskeleton assemble and elongation machinery and inhibiting apoptosis $[22,23]$. In the liver, the expression level of STEAP3 was reported to be substantially diminished in HCC nodules compared with cirrhotic peritumoral tissues and is dependent on tumor differentiation stage, with lower levels of STEAP3 associated with moderately or poorly differentiated tumors $[18,19]$. Nevertheless, in our present study, for the first time, an aberrant nuclear expression pattern of STEAP3 was observed, which correlated with tumor differentiation and predicted poor prognosis, supporting its oncogenic role in the progression of HCC. Furthermore, enhanced nuclear expression of STEAP3 promotes cancer cell proliferation by enhancing stemness phenotype and accelerating G1/S transition through regulating intracellular signaling and facilitating nuclear trafficking of EGFR.

Nuclear translocation of EGFR was first found in hepatocytes that underwent regeneration [24]. Nuclear EGFR correlates with poor outcomes in multiple human malignancies, including breast cancer [25], ovarian cancer [26], non-small cell lung cancer (NSCLC) [27], and oropharyngeal squamous carcinoma [28]. In addition, the nuclear localization of EGFR is responsible for resistance to EGFRtargeted therapies and cisplatin [29-31]. Due to lack of a putative DNA binding domain, activated nuclear EGFR act as a transcriptional co-factor to modulate certain target genes, such as iNOS, Aurora-A, $\mathrm{c}-\mathrm{Myc}$, and B-Myb, through association with transcriptional factors that harbor DNA binding capability, including STAT3 [20, 32-34]. However, the subcellular trafficking mechanism of EGFR hasn't been fully explored yet. Previous study showed that importin- $\beta$ and CRM1 form a complex with EGFR to facilitate its nuclear translocation [35]. In this study, we reveal that STEAP3 facilitated translocation as a new mechanism of EGFR nuclear trafficking in HCC cells. In the nucleus, STEAP3 and EGFR together enhance the transactivity of STAT3. In addition to HCC cells, similar interaction between STEAP3 and EGFR was observed in HEK293, suggesting it might be a common functional role of STEAP3 in human cancers.

In the present study, we found that STEAP3 modulates EGFR-ERKSTAT3 and JNK-STAT6 signaling to promote HCC cells proliferation. Constitutive activation of STAT family members, which possess properties of oncogenes, has been demonstrated in several human malignancies [36]. Increased activity of STAT3 induced by EGFR has been found in breast, prostate, lung, head, and neck, pancreatic and colon cancer [36-40]. STAT6 is also constitutively activated and involved in tumor initiation and progression [41-43]. Persistent activation of STAT6 is responsible for promoting the local proinflammatory response to favor the development of colitisassociated colon cancer [42]. Ser707 phosphorylation of STAT6 by JNK was reported to play a role in crosstalk between the intracellular signals of IL-4 and IL-1 $\beta$ by negatively regulating IL-4-induced transcriptional activation of STAT6 [44]. However, STAT6 possesses five potential phosphorylation sites that match the consensus substrate sequences of JNK, implying that JNK-STAT6 signaling might exert different functions in a context-dependent way. In this study, STEAP3 activated JNK to upregulate Tyr641 phosphorylation of STAT6 to promote transcription of IL-8 and IL-18, which have protumoral functions through regulating angiogenesis, survival signaling, and immunosuppression $[45,46]$.

RAC1, a member of the Rho family of small GTPases that acts as molecular switch through GDP-bound inactive and GTP-bound active states and regulates a wide range of cellular processes, including cell proliferation, differentiation, survival, motility, nuclear and cytoskeleton assembly, was recently reported that its nuclear translocation associates with carcinogenesis and enhanced aggressiveness of cancer. As a signaling hub integrating receptorassociated intracellular signaling into dynamic cellular response, RAC1 has been shown to be a critical component of EGFR signaling in various tumors and implicated in regulating ERK/JNK signaling $[47,48]$. EGFR stimulated ERK activation phosphorylates RAC1 on Thr108 and targets RAC1 for nuclear translocation [49]. Nuclear RAC1 
could modulate nuclear shape and position in an actin-dependent fashion and alter nuclear membrane fluidity and order [50, 51]. Therefore, as we observed in our study, nuclear importing of RAC1 prior to that of EGFR after their interaction in the cytoplasm and its interaction with Lamin A/C might change the nucleus to be more accessible to EGFR trafficking.

In summary, our study revealed, for the first time, the nuclear expression pattern of STEAP3 in human HCC tissues. Our results support the concept that up-regulated nuclear expression of STEAP3 plays an important role in the acquisition of a poor prognostic phenotype in HCC. In addition, functional and mechanistic studies suggest that STEAP3 participates in promoting HCC cell proliferation through modulating nuclear trafficking of EGFR and the activities of EGFR-RAC1-ERK-STAT3 and RAC1-JNK-STAT6 axes, which might be contributed, at least in part, to the progression of human HCC.

\section{DATA AVAILABILITY}

The data that support the findings of this study are available from the corresponding author upon reasonable request.

\section{REFERENCES}

1. Bray F, Ferlay J, Soerjomataram I, Siegel RL, Torre LA, Jemal A. Global cancer statistics 2018. GLOBOCAN estimates of incidence and mortality worldwide for 36 cancers in 185 countries. CA Cancer J Clin. 2018;68:394-424.

2. McGlynn KA, Tsao L, Hsing AW, Devesa SS, Fraumeni JF Jr. International trends and patterns of primary liver cancer. Int J Cancer. 2001;94:290-6.

3. Imamura $\mathrm{H}$, Matsuyama $\mathrm{Y}$, Tanaka E, Ohkubo T, Hasegawa K, Miyagawa $\mathrm{S}$, et al. Risk factors contributing to early and late phase intrahepatic recurrence of hepatocellular carcinoma after hepatectomy. J Hepatol. 2003;38:200-7.

4. Arizumi T, Ueshima $K$, Iwanishi $M$, Minami T, Chishina $H$, Kono $M$, et al. The overall survival of patients with hepatocellular carcinoma correlates with the newly defined time to progression after transarterial chemoembolization. Liver Cancer. 2017;6:227-35.

5. Ohgami RS, Campagna DR, Greer EL, Antiochos B, McDonald A, Chen J, et al. Identification of a ferrireductase required for efficient transferrin-dependent iron uptake in erythroid cells. Nat Genet. 2005;37:1264-9.

6. Passer BJ, Nancy-Portebois V, Amzallag N, Prieur S, Cans C, Roborel de Climens A et al. The p53-inducible TSAP6 gene product regulates apoptosis and the cell cycle and interacts with Nix and the Myt1 kinase. Proc Natl Acad Sci USA. 2003;100:2284-9.

7. Ohgami RS, Campagna DR, Antiochos B, Wood EB, Sharp JJ, Barker JE, et al. nm1054: a spontaneous, recessive, hypochromic, microcytic anemia mutation in the mouse. Blood. 2005;106:3625-31.

8. Grandchamp B, Hetet G, Kannengiesser C, Oudin C, Beaumont C, RodriguesFerreira $S$, et al. A novel type of congenital hypochromic anemia associated with a nonsense mutation in the STEAP3/TSAP6 gene. Blood. 2011;118:6660-6.

9. Lespagnol A, Duflaut D, Beekman C, Blanc L, Fiucci G, Marine JC, et al. Exosome secretion, including the DNA damage-induced p53-dependent secretory pathway, is severely compromised in TSAP6/Steap3-null mice. Cell Death Differ. 2008;15:1723-33.

10. Amzallag N, Passer BJ, Allanic D, Segura E, Théry C, Goud B, et al. TSAP6 facilitates the secretion of translationally controlled tumor protein/histamine-releasing factor via a nonclassical pathway. J Biol Chem. 2004;279:46104-12.

11. Wells NJ, Watanabe N, Tokusumi T, Jiang W, Verdecia MA, Hunter T. The C-terminal domain of the $\mathrm{Cdc} 2$ inhibitory kinase Myt1 interacts with Cdc2 complexes and is required for inhibition of $\mathrm{G}(2) / \mathrm{M}$ progression. J Cell Sci. 1999;112:3361-71.

12. Yussman MG, Toyokawa T, Odley A, Lynch RA, Wu G, Colbert MC, et al. Mitochondrial death protein Nix is induced in cardiac hypertrophy and triggers apoptotic cardiomyopathy. Nat Med. 2002;8:725-30.

13. Hubert RS, Vivanco I, Chen E, Rastegar S, Leong K, Mitchell SC, et al. STEAP: a prostate-specific cell-surface antigen highly expressed in human prostate tumors. Proc Natl Acad Sci USA. 1999;96:14523-8.

14. Broner EC, Tropé CG, Reich R, Davidson B. TSAP6 is a novel candidate marker of poor survival in metastatic high-grade serous carcinoma. Hum Pathol. 2017;60:180-7.

15. Isobe T, Baba E, Arita S, Komoda M, Tamura S, Shirakawa T, et al. Human STEAP3 maintains tumor growth under hypoferric condition. Exp Cell Res. 2011;317:2582-91.

16. Rishi G, Subramaniam VN. The liver in regulation of iron homeostasis. Am J Physiol Gastrointest Liver Physiol. 2017;313:G157-G165.
17. Guo WZ, Fang HB, Cao SL, Chen SY, Li J, Shi JH, et al. Six-transmembrane epithelial antigen of the prostate 3 deficiency in hepatocytes protects the liver against ischemia-reperfusion injury by suppressing transforming growth factor$\beta$-activated kinase 1. J Hepatol. 2020;71:1037-54.

18. Caillot F, Daveau R, Daveau M, Lubrano J, Saint-Auret G, Hiron M, et al. Downregulated expression of the TSAP6 protein in liver is associated with a transition from cirrhosis to hepatocellular carcinoma. Histopathology. 2009;54:319-27.

19. Coulouarn C, Derambure C, Lefebvre G, Daveau R, Hiron M, Scotte M, et al. Global gene repression in hepatocellular carcinoma and fetal liver, and suppression of dudulin-2 mRNA as a possible marker for the cirrhosis-to-tumor transition. J Hepatol. 2005;42:860-9.

20. Lo HW, Hsu SC, Ali-Seyed M, Gunduz M, Xia W, Wei Y, et al. Nuclear interaction of EGFR and STAT3 in the activation of the iNOS/NO pathway. Cancer Cell. 2005;7:575-89.

21. De P, Aske JC, Dey N. RAC1 Takes the Lead in Solid Tumors. Cells. 2019;8:382.

22. Gachet $Y$, Tournier S, Lee M, Lazaris-Karatzas A, Poulton T, Bommer UA. The growth-related, translationally controlled protein $\mathrm{P} 23$ has properties of a tubulin binding protein and associates transiently with microtubules during the cell cycle. J Cell Sci. 1999;112:1257-71.

23. Tuynder M, Susini L, Prieur S, Besse S, Fiucci G, Amson R, et al. Biological models and genes of tumor reversion: cellular reprogramming through tpt1/TCTP and SIAH-1. Proc Natl Acad Sci USA. 2002;99:14976-81.

24. Marti U, Burwen SJ, Wells A, Barker ME, Huling S, Feren AM, et al. Localization of epidermal growth factor receptor in hepatocyte nuclei. Hepatology. 1991;13:15-20.

25. Lo HW, Xia W, Wei Y, Ali-Seyed M, Huang SF, Hung MC. Novel prognostic value of nuclear epidermal growth factor receptor in breast cancer. Cancer Res. 2005;65:338-48.

26. Xia W, Wei Y, Du Y, Liu J, Chang B, Yu YL, et al. Nuclear expression of epidermal growth factor receptor is a novel prognostic value in patients with ovarian cancer. Mol Carcinog. 2009;48:610-7.

27. Traynor AM, Weigel TL, Oettel KR, Yang DT, Zhang C, Kim K, et al. Nuclear EGFR protein expression predicts poor survival in early stage non-small cell lung cancer. Lung Cancer. 2013;81:138-41.

28. Psyrri A, Yu Z, Weinberger PM, Sasaki C, Haffty B, Camp R, et al. Quantitative determination of nuclear and cytoplasmic epidermal growth factor receptor expression in oropharyngeal squamous cell cancer by using automated quantitative analysis. Clin Cancer Res. 2005;11:5856-62.

29. Huang WC, Chen YJ, Li LY, Wei YL, Hsu SC, Tsai SL, et al. Nuclear translocation of epidermal growth factor receptor by Akt-dependent phosphorylation enhances breast cancer-resistant protein expression in gefitinib-resistant cells. J Biol Chem. 2011;286:20558-68.

30. Li C, lida M, Dunn EF, Ghia AJ, Wheeler DL. Nuclear EGFR contributes to acquired resistance to cetuximab. Oncogene. 2009;28:3801-13.

31. Hsu SC, Miller SA, Wang Y, Hung MC. Nuclear EGFR is required for cisplatin resistance and DNA repair. Am J Transl Res. 2009;1:249-58.

32. Hung LY, Tseng JT, Lee YC, Xia W, Wang YN, Wu ML, et al. Nuclear epidermal growth factor receptor (EGFR) interacts with signal transducer and activator of transcription 5 (STAT5) in activating Aurora-A gene expression. Nucleic Acids Res. 2008;36:4337-51.

33. Jaganathan $S$, Yue $P$, Paladino DC, Bogdanovic J, Huo Q, Turkson J. A functional nuclear epidermal growth factor receptor, SRC and Stat3 heteromeric complex in pancreatic cancer cells. PLoS One. 2011;6:e19605.

34. Hanada N, Lo HW, Day CP, Pan Y, Nakajima Y, Hung MC. Co-regulation of B-Myb expression by E2F1 and EGF receptor. Mol Carcinog. 2006;45:10-17.

35. Lo HW, Ali-Seyed M, Wu Y, Bartholomeusz G, Hsu SC, Hung MC. Nuclearcytoplasmic transport of EGFR involves receptor endocytosis, importin beta1 and CRM1. J Cell Biochem. 2006;98:1570-83.

36. Bowman T, Garcia R, Turkson J, Jove R. STATs in oncogenesis. Oncogene. 2000;19:2474-88.

37. Haura EB, Zheng Z, Song L, Cantor A, Bepler G. Activated epidermal growth factor receptor-Stat-3 signaling promotes tumor survival in vivo in non-small cell lung cancer. Clin Cancer Res. 2005;11:8288-94.

38. Grandis JR, Pietenpol JA, Greenberger JS, Pelroy RA, Mohla S. Head and neck cancer: meeting summary and research opportunities. Cancer Res. 2004;64:8126-9.

39. Buettner R, Mora LB, Jove R. Activated STAT signaling in human tumors provides novel molecular targets for therapeutic intervention. Clin Cancer Res. 2002;8:945-54

40. Atreya R, Neurath MF. Signaling molecules: the pathogenic role of the IL-6/STAT-3 trans signaling pathway in intestinal inflammation and in colonic cancer. Curr Drug Targets. 2008;9:369-74.

41. Das $S$, Roth CP, Wasson LM, Vishwanatha JK. Signal transducer and activator of transcription-6 (STAT6) is a constitutively expressed survival factor in human prostate cancer. Prostate. 2007;67:1550-64. 
42. Leon-Cabrera SA, Molina-Guzman E, Delgado-Ramirez YG, Vázquez-Sandoval A, Ledesma-Soto Y, Pérez-Plasencia CG, et al. Lack of STAT6 attenuates inflammation and drives protection against early steps of colitis-associated colon cancer. Cancer Immunol Res. 2017;5:385-96.

43. Merk BC, Owens JL, Lopes MB, Silva CM, Hussaini IM. STAT6 expression in glioblastoma promotes invasive growth. BMC Cancer. 2011;11:184.

44. Shirakawa T, Kawazoe Y, Tsujikawa T, Jung D, Sato S, Uesugi M. Deactivation of STAT6 through serine 707 phosphorylation by JNK. J Biol Chem. 2011;286:4003-10.

45. Alfaro C, Sanmamed MF, Rodríguez-Ruiz ME, Teijeira Á, Oñate C, González Á, et al. Interleukin-8 in cancer pathogenesis, treatment and follow-up. Cancer Treat Rev. 2017;60:24-31.

46. Baker KJ, Houston A, Brint E. IL-1 family members in cancer; two sides to every story. Front Immunol. 2019;10:1197.

47. De P, Rozeboom BJ, Aske JC, Dey N. Active RAC1 promotes tumorigenic phenotypes and therapy resistance in solid tumors. Cancers (Basel). 2020;12:1541.

48. Hudson LG, Gillette JM, Kang H, Rivera MR, Wandinger-Ness A. Ovarian tumor microenvironment signaling: convergence on the Rac1 GTPase. Cancers (Basel). 2018;10:358

49. Tong J, Li L, Ballermann B, Wang Z. Phosphorylation of Rac1 T108 by extracellular signal-regulated kinase in response to epidermal growth factor: a novel mechanism to regulate Rac1 function. Mol Cell Biol. 2013;33:4538-51.

50. Phuyal S, Farhan H. Multifaceted Rho GTPase signaling at the endomembranes. Front Cell Dev Biol. 2019;7:127.

51. Navarro-Lérida I, Pellinen T, Sanchez SA, Guadamillas MC, Wang Y, Mirtti T, et al. Rac1 nucleocytoplasmic shuttling drives nuclear shape changes and tumor invasion. Dev Cell. 2015;32:318-34.

\section{ACKNOWLEDGEMENTS}

This work was supported by the National Key R\&D Program of China (Grant No. 2017YFC1309001) and the Natural Science Foundation of Guangdong Province, China (Grant No. 2018A0303130255).

\section{AUTHOR CONTRIBUTIONS}

L-LW: conceptualization, methodology, investigation, and writing-original draft; JL: investigation, validation, and formal analysis; Z-HH: investigation and resources; Y-QL: data curation; H-GL: visualization; DX: project administration; M-YC: supervision, writing-review \& editing. The authors read and approved the final version of the manuscript.

\section{COMPETING INTERESTS}

The authors declare no competing interests.

\section{ETHICS STATEMENT}

Using of human tissues in this study was reviewed and approved by Ethical Committee of Sun Yat-Sen University Cancer Center. Animal experiment was carried out following the Guide for the Care and Use of Laboratory Animals (2011) and approved by the Animal Ethical and Welfare Committee (AEWC) of Sun Yat-Sen University (No. L102012018110B).

\section{ADDITIONAL INFORMATION}

Supplementary information The online version contains supplementary material available at https://doi.org/10.1038/s41419-021-04329-9.

Correspondence and requests for materials should be addressed to Dan Xie or MuYan Cai.

Reprints and permission information is available at http://www.nature.com/ reprints

Publisher's note Springer Nature remains neutral with regard to jurisdictional claims in published maps and institutional affiliations. (c) (i)

Open Access This article is licensed under a Creative Commons Attribution 4.0 International License, which permits use, sharing, adaptation, distribution and reproduction in any medium or format, as long as you give appropriate credit to the original author(s) and the source, provide a link to the Creative Commons license, and indicate if changes were made. The images or other third party material in this article are included in the article's Creative Commons license, unless indicated otherwise in a credit line to the material. If material is not included in the article's Creative Commons license and your intended use is not permitted by statutory regulation or exceeds the permitted use, you will need to obtain permission directly from the copyright holder. To view a copy of this license, visit http://creativecommons. org/licenses/by/4.0/.

(c) The Author(s) 2021 